\title{
Presupposition as investigator certainty in a police interrogation: The case of Lorenzo Montoya's false confession
}

\section{Author: Philip Gaines}

This is a postprint of an article that originally appeared in Discourse \& Society on July 2018. The final version can be found at https://dx.doi.org/10.1177/0957926518754417.

Gaines, Philip. "Presupposition as investigator certainty in a police interrogation: The case of Lorenzo Montoya's false confession." Discourse \& Society 29, no. 4 (July 2018): 399-419. DOI:10.1177/0957926518754417. 


\title{
Presupposition as investigator certainty in a police interrogation: The case of Lorenzo Montoya's false confession
}

\author{
Philip Gaines \\ Montana State University, USA
}

\begin{abstract}
This article presents an analysis of the use by police investigators of presupposition-bearing questions (PBQs) in interrogation as a process for communicating certainty of guilt. Among the techniques of interrogational maximization employed by police is the communication to the suspect of the interrogators' certainty of the suspect's guilt. While social science research notes that such communication of certainty is given directly, for example by statements that they 'know' the suspect is guilty or by direct accusations such as 'you did it', this analysis shows that certainty of guilt can also be communicated by presuppositions embedded in interrogation questions. Discourse analysis of the complete transcript of the interrogation of a 14-year-old suspect reveals further that through the use of 177 PBQs, interrogators are able to accrue inadvertent admissions to three crucial global 'facts' about the suspect's involvement in the crime - each of which is composed of multiple subsidiary 'facts'. In addition to identifying the role of PBQs in eliciting inadvertent admissions, the analysis also notes how PBQs serve as 'a powerful instrument in the implicit assertion of debatable propositions' as part of the interrogational record.
\end{abstract}

\section{Keywords}

police interrogation, false confession, presupposition 


\section{The unjust conviction of Lorenzo Montoya}

Lorenzo Montoya (LM) was arrested, at age 14, in January of 2000 and charged, along with acquaintance Nick Martinez and Nick's cousin JR Martinez, with the murder of 29-year-old Emily Johnson at her Denver, Colorado home. On 10 January, Lorenzo was interrogated for just over 2 hours. In spite of his many denials of guilt in the first half the interview, the detectives eventually elicited a confession by Lorenzo later in the interrogation that he had participated in the beating and death of the victim and the theft of her car. On 3 November, Lorenzo was convicted of felony murder and was given a prison sentence of life without the possibility of parole.

After several years, Lorenzo's case was taken up by attorney Lisa Polansky at the Denver Center for Juvenile Justice. A subsequent investigation revealed evidence that ultimately resulted in exoneration for Lorenzo, the most compelling of which was testing that excluded Lorenzo's DNA at sites critical to the prosecution's case. Lorenzo's conviction was vacated on 16 June 2014 and the charges dismissed in exchange for a guilty plea to being an accessory after the fact, since Lorenzo had ridden in the stolen car the day after the murder yet withheld details of the crime that were shared with him by Nick and JR. ${ }^{1}$

\section{The interrogation transcript}

The fact that Lorenzo was not guilty of the crimes for which he was tried and convicted entails the additional fact that his confession was false. Analyzing the transcript of an interrogation which results in a false confession provides a rare opportunity to explore - without the complicating element of crime facts being contributed by the suspect and subsequently integrated by the interviewers - the linguistic and discursive realizations of the methods and techniques utilized by police in coercive interrogations, such as those recommended and taught in the United States by the Reid school of crime investigation. The following analysis is based on just such a transcript.

Lorenzo's interrogation began at 8:00 p.m. and was conducted by detectives Martinez and Vigil. For the first 40 minutes Lorenzo's mother was in the room. After she was excused, the interrogation continued for another 90 minutes. Important contextual elements include the fact that Nick was being interrogated at the same time in another room and that the police were in possession of a pair of shoes and a jacket that were linked to the crime scene - items which they claimed belonged to Lorenzo. The interrogation session under analysis here was videotaped in its entirety and a police transcript ${ }^{2}$ produced $^{-}$ from the tape 3 days later. Worthy of note is that Lorenzo gave no audible response to many of the questions posed by the interrogators. The video shows that Lorenzo's nonresponses were accompanied by him having his head down.

\section{Presupposition in interrogation questions}

This article presents an analysis of the use by investigators of presupposition-bearing questions (PBQs) in interrogation as a technique for communicating certainty of guilt. Before beginning the analysis, I offer a brief excursus on syntactic presupposition with particular emphasis on presuppositions in questions. 
At the level of syntax, a presupposition in a sentence is an embedded proposition that is assumed to be true. As Stalnaker (1978) has it, 'Presuppositions are what are taken by the speaker to be the common ground of the participants in the conversation' (p. 321). Presuppositions can be as simple as a definite description: 'John saw the man with two heads.' Here, there are two presuppositions - that there was a man who was seen and that the man had two heads. Presupposition can also be embedded in factive constructions: 'Martha regrets eating' (Presupposition: Martha ate) or 'John wasn't aware that Bill was there' (Presupposition: Bill was there) The previous examples are taken from Levinson's list of 'presupposition triggers'. For Levinson (1983), 'the technical sense of presupposition [involves] certain pragmatic inferences or assumptions that seem ... to be built into linguistic expressions and can be isolated using specific linguistic tests' (p. 168).

Of particular interest for this analysis is the role of presuppositions in questions. Since 'every question presupposes precisely that at least one of its direct answers is true' (Belnap, 1966: 610), a question containing a presupposition necessarily assumes that the presupposition is true. For example, in a $w h$-question such as 'Where did you put the shovel?', the question presupposes that the hearer indeed put the shovel somewhere and only seeks to find out where it was put. In a yes/no question such as 'Did you put the shovel in the cellar?', it is presupposed that the hearer did put the shovel somewhere and only seeks to find out whether the cellar was the place where it was put.

Questions containing presuppositions can put a hearer accused - but innocent - of a bad act in a difficult position when he or she is being interrogated. As above, in the case of a yes/no question such as

Have you stopped shoplifting yet?

an answer of either 'yes' or 'no' does not 'disconfirm the proposition contained' (Ehrlich and Sidnell, 2006: 658) in the question, that is, that the addressee has had a habit of shoplifting. The only way for the addressee to avoid an admission is to refuse to give a 'yes' or 'no' answer and instead to state that he or she does not accept the embedded accusatory proposition. In speech act terms, the hearer sees the question as not felicitous since '[a] yes/no question can be felicitous only if neither an affirmative nor a negative answer would clash with its presuppositions' (Derzhanski, 2000: 2). It is not surprising that yes/ no questions are also referred to as 'forced-choice' questions.

In the case of a wh-question such as

Why haven't you stopped shoplifting?

it is again presupposed that the addressee has a history of shoplifting, but also includes the additional presupposition that the addressee has a reason for not having stopped. In order to avoid an admission, the addressee will be forced to violate Grice's maxim of quantity by not supplying the questioner with the information sought. Again, in order to maintain a claim of innocence, the addressee must resort to a refusal to accept the presupposed premise. 


\section{PBQs in the LM interrogation}

The transcript of the interrogation of LM contains (by my count) 117 PBQs - many bearing multiple presuppositions. In my experience of examining interrogation transcripts, this is an unusually high concentration of such questions. With few exceptions, these PBQs are found in yes/no or wh-question types; many are repeated verbatim. Typically, Lorenzo responds to PBQs with silence. On numerous occasions, however, he gives a direct answer, thus inadvertently (as we will see) confirming the presupposition. Occasionally, Lorenzo refuses to give a direct answer and instead challenges the premise of the presupposition.

Lorenzo's inadvertent confirmation of presuppositions occurs frequently enough that the interrogators are able to accrue admissions to three crucial global 'facts' about his involvement in the crime - each of which is composed of multiple subsidiary 'facts' - as follows:

1. Lorenzo was one of the co-conspirators

1.1. He was associated with Nick prior to the commission of the crime

1.2. He was associated with both with Nick and JR prior to the commission of the crime

2. Lorenzo was at the scene of the crime

2.1. He went to the crime scene with Nick and JR

2.2. He was at the victim's house

2.3. His footprints were found at the scene

3. Lorenzo was directly involved in the murder

3.1. He was one of the culpable parties with an individual role in the crime.

3.2. He participated in the crime out of intimidation or to show solidarity

3.3. He was actively involved in the killing

The analysis examines the PBQs that contribute to the construction of the subsidiary 'facts' that underlie the global 'facts'. In the following excerpts text in bold type contains a PBQ, and text in both bold and shaded type contains both a PBQ and a presuppositionconfirming response by LM. The investigators are police officers Martin Vigil (MV) and Mike Martinez (MM). As mentioned, LM's mother Mary Torres (MT) was also present at the beginning of the interrogation.

\section{LM was one of the co-conspirators}

The first global fact advanced by the investigators is that LM was one of the criminal co-conspirators, specifically that he was a member of a group of three - LM, Nick, and JR - that gathered the night of the crime for nefarious purposes. (Note: Prior to the recorded interview, LM had admitted in another conversation with the police that in the early afternoon the day after the crime, Nick had come by his home to give him a ride in the car he had stolen from the victim's house at which time Nick had revealed that JR had participated in the crime with him and also revealed certain of their activities at the crime scene. This account by LM provides the propositional raw material on which a series of accusatory presuppositions are then based.) 
LM was associated with Nick prior to the commission of the crime. In a series of PBQs, MM and MV posit that LM was associated with Nick - a friend of his cousin and a person already deeply implicated in the murder:

\begin{tabular}{|c|c|c|}
\hline 49:14 & MM: & How did you and Nick hook- hook up? \\
\hline $\begin{array}{l}49: 15 \\
49: 16\end{array}$ & LM: & $\begin{array}{l}\text { I don't even know Nick. I know him through } \\
\text { my cousin. }\end{array}$ \\
\hline $\begin{array}{l}49: 17 \\
49: 18\end{array}$ & MM: & $\begin{array}{l}\text { Well, how did you guys hook up? How'd you hook } \\
\text { up with Nick? }\end{array}$ \\
\hline 49:19 & MT: & With Nick? \\
\hline 49:20 & MM: & What time? What time that morning? \\
\hline 49:21 & LM: & It was like in the evening or afternoon. \\
\hline 49:22 & MM: & No, I'm talkin' about the mornin'. \\
\hline 49:23 & LM: & $\varnothing$ \\
\hline 49:24 & MM: & You guys lookin' for cars to break into? \\
\hline $49: 25$ & LM: & No. \\
\hline $\begin{array}{l}50: 1 \\
50: 2\end{array}$ & MM: & $\begin{array}{l}\text { One person on one side of the street, the other } \\
\text { person on the other side of the street? }\end{array}$ \\
\hline $\begin{array}{l}59: 15 \\
59: 16\end{array}$ & MV: & $\begin{array}{l}\text { Yeah, you guys went lookin' for a car to jack, } \\
\text { didn't ya? A car to take. }\end{array}$ \\
\hline $59: 17$ & LM: & I don’t even know ... \\
\hline
\end{tabular}

MM's questions at 49:14, 17, and 20 ostensibly seek to discover 'how' and at 'what time' LM and Nick 'hooked up' - crucially, by first presupposing that they did so. This is the first of many PBQs that follow the pattern of seeking additional information regarding a 'fact' that has been presupposed.

The exchange at 49:20-21 is also the first of several instances in which LM apparently misunderstands the context of a question and gives a response that inadvertently confirms the presupposition. In this case, when MM seeks information as to the circumstances of LM and Nick supposedly 'hooking up' prior to the commission of the crime, LM answers that 'it' - that is, in his understanding the time when Nick showed up after the murder with the stolen car - was 'in the afternoon or evening'. Although the timeframe is different from that specified by MM (see 49:20, 22), LM's admission that he hooked up with Nick ends up confirming MM's presupposition that LM was associated with Nick prior to commission of the crime.

PBQs at 49:24, 50:1-2, and 59:15-16 again presuppose that LM and Nick were associated prior to the murder for the purpose of planning a car break-in and theft. LM's answer of 'no' at 49:25, while denying that their reason for being together involved breaking into cars, nevertheless again confirms MM's presupposition that LM and Nick were associated prior to the murder; that is, the denial only applies to the reason the 'guys' were together, leaving the presupposition intact.

LM was associated with both Nick and JR prior to the commission of the crime. In three separate portions of the interview, MV asks a number of PBQs that assume that LM was associated with both Nick and JR prior to the murder. (Note that JR was not with Nick when the latter went to LM's house to show off the stolen car.) 
77:11 MV: Where'd they pick you up at? Where did you

77:12 LM: [They didn't ]

77:13 MV: [meet up with 'em]

77:14 LM: [pick me up ].

77:15 MV: [where did you meet them at]?

77:16 LM: I didn't meet them nowhere sir. I don't even

77:17 know-

77:18 MV: Lorenzo! You know 'em. Now where did you guys

77:19 meet up that night before you went to the house? What street?

77:20 LM: Ø

77:25 MV: Where did you guys meet up at first before you

77:26 went into the house? What street?

77:27 LM: Didn't meet up at no street. [I wasn't there. ]

78:1 MV: [Where did you meet up?] You were there.

79:23 MV: 'Kay. Now where did you meet up with JR and

79:24 Nick at?

79:25 LM: I didn't meet up with JR or Nick, sir.

79:26 MV: Then how'd you get to the house?

79:27 LM: ø

86:22 MV: Where did you meet Nick and JR at?

86:23 LM: Ø

86:24 MV: Where did you meet them at that night?

86:26 Lorenzo? I'm not [gonna

86:27 LM: [(unintelligible)]

87:1 MV: [pull words outta] You met 'em where?

87:2 LM: Didn't meet them that night, mister.

87:3 MV: Where did you meet 'em at?

87:6 This had to start some place; where's that at?

87:8 MV: Lorenzo?

87:9 LM: Right there on Ninth.

87:10 MV: Ninth and what?

87:11 LM: Newton.

87:12 MV: 'Kay, you met JR and Nick at Ninth and Newton,

87:13 right?

87:14 LM: ø

MV's questions here presuppose that the three met up somewhere - crucially 'that night' (86:24) before they went 'to the house' $(77: 19,79: 26)$ and 'into the house' $(77: 26)$, additional presuppositions about LM's involvement - and that said meeting up included Nick and JR. Through no less than 13 questions, MV does not receive a confirmation of his presupposition - instead only denials or silence from LM. However, at 87:6ff, MV's reformulation of the question generates a second misunderstanding on LM's part: in response to the question of where 'this' started, LM answers with a specific location $(87: 9,11)$ - making it clear that he understands 'this' as the time Nick came by his house the morning after the murder to show him the car they had stolen (something LM had already explained to MV and MM) - whereas for MV, 'this' was the staging of the crime. LM's answer thus inadvertently confirms MV's presupposition that LM had a preplanned gathering with Nick and JR prior to the murder. 


\section{$L M$ was at the scene of the crime}

A second global fact posited by the investigators through PBQs is that LM was at the scene of the crime. For MM and MV, this is established with three subsidiary facts: that LM went to the crime scene with Nick and JR, that LM was at the victim's house, and that LM's footprints were found at the scene.

LM went to the crime scene with Nick and JR. At 46:23-26, MV first advances the notion that LM had 'made a mistake' - first by going in the car with Nick and JR and then by going with them to 'the murder scene':

46:23 MV: $\quad$... you made a mistake. You

46:24 made a mistake goin' with these guys; you didn't only make a mistake

46:25 goin' in the car, you made a mistake goin' to the murder scene with

46:26 these guys ...

Then at 47:18, MM incorporates this 'mistake' explanation into a question presupposing that LM had, in fact, made this mistake:

$\begin{array}{lll}\text { 47:18 } & \text { MM: } & \text { It was a mistake, though, wasn't it? Were [you } \\ \text { 47:19 } & \text { MT: } & \\ \text { 47:20 } & \text { MM } & \text { high at the time? } \\ \text { 47:21 } & \text { LM: } & \text { No! } \\ \text { 47:22 } & \text { MM: } & \text { [Let me ask you } \\ 47: 23 & \text { MT: } & \text { [You weren't there? } \\ \text { 47:24 } & \text { MM: } & \text { Were you high at the time? } \\ \text { 47:25 } & \text { LM: } & \text { Yes. }\end{array}$

The pronoun 'it' in 47:18 has as its referent going in the car with the others to the murder scene. Identifying these actions as a 'mistake' employs a factive which presupposes that 'it' occurred. The question ostensibly seeks confirmation from LM that it was a mistake. The unanswered tag question seeks a yes/no answer, either of which would have allowed the presupposition to survive. (Note: LM's emphatic 'No!' at 47:21 is in response to his mother MT's question as to whether he was 'there' - that is, at the murder scene.)

At 47:18-20 and 24, MM asks LM whether he was high at 'the time' - a deictic that references the occasion of the mistake of going in the car with the others to the crime scene. Use of 'the time' clearly specifies given information, but MM and LM assign different meanings to it - a critical failure of communication that soon results in an apparent admission by LM. In light of LM's adamant denial to MT that he was at the murder scene, his response of 'yes' at 47:25 clearly indicates that he does not share MM's meaning for 'the time'. Since he had already admitted to having ridden in the car with Nick the day after the crime, his answer of 'yes' signals his understanding that the period covering only this activity was 'the time' being referred to by MM. The error in interpretation allows his answer to unwittingly confirm the presupposition that was explicitly posited earlier and then elided from the noun phrase 'the time', that is, 'the time [that you went in the car with Nick and JR - including going to the murder scene]'. 
LM's accidental self-inculpation is then repeated twice more:

\begin{tabular}{|c|c|c|}
\hline $\begin{array}{l}48: 12 \\
48: 13\end{array}$ & MM: & $\begin{array}{l}\text { So, you just didn't know what you were doin' } \\
\text { because you were high on marijuana? }\end{array}$ \\
\hline 48:16 & LM: & Yes. \\
\hline $\begin{array}{l}48: 17 \\
48: 18\end{array}$ & MT: & $\begin{array}{l}\text { Were you with this- were you with them when } \\
\text { they- }\end{array}$ \\
\hline $48: 19$ & LM: & No!! Sh- ... \\
\hline $\begin{array}{l}48: 20 \\
48: 21\end{array}$ & MM: & $\begin{array}{l}\text { You can't convince me of that Lorenzo. You were } \\
\text { high at the time. Was everybody else high? }\end{array}$ \\
\hline 48:22 & LM: & Yes. \\
\hline $48: 23$ & MM: & Nick was high? What was Nick high on? \\
\hline 48:24 & LM: & Weed. \\
\hline $48: 25$ & MM: & Weed? Junior? \\
\hline $48: 26$ & LM: & I don't know for sure. \\
\hline $48: 27$ & MM: & What was he high on? \\
\hline $49: 1$ & LM: & Probably weed, too. \\
\hline
\end{tabular}

At 48:12, MM recruits another factive - 'you didn't know' - to establish the fact that LM '[was] doin[g]' something; the because subordinate clause included in this yes/no question seeks confirmation from LM of the proposed reason (being high) for what is presupposed to have happened. LM's response of 'yes' at 48:16 demonstrates another instance of the failure in communication seen earlier. For LM, "what [he was] doin" was riding around in a stolen car with Nick, the confessed perpetrator of the crime. For MM, however, "what [LM was] doin" included (at least) going in the car to the crime scene with Nick and JR. Thus, LM's admission at 48:16 to having ridden in the car with Nick while high on marijuana ends up inadvertently confirming MM's presupposition that he had gone to the crime scene with Nick and JR. Then, at 48:22, LM repeats his accidental admission in response to the question 'Was everybody else high [at the time that you and the others went in the car to the murder scene?]' - the elided material in brackets, which includes the presupposition, being recoverable but crucially not understood by LM.

The same misunderstanding appears at 49:2-7:

49:2 MM: 'Kay. Was, was Junior not there? Was it just

49:3 you and Nick?

49:5 Was that the whole deal? It was just you and

49:6 Nick?

49:7 LM: No.

MM's question 'Was it just you and Nick?' presupposes that it was at least LM and Nick who went to the crime scene. LM's understanding of 'it', however, is the fact of him, his brother Fred, and his friend Luke - the latter two having also been in the initial joyriding party - being together in the stolen car with Nick. Thus, LM's clarifying answer of 'no' to the question of whether it was just him and Nick inadvertently confirms MM's presupposition that he, Nick, and JR were all involved in traveling together to the scene of the crime. It is clear that LM is thoroughly confused at this point. 
At 56:6, MV seeks information about what happened at the crime scene when LM and the others 'were high on marijuana' - now an established reason (for MM and MV) for the boys' criminal actions:

\section{6:6 MV: ... Now, you said you were high on marijuana, what happened? \\ 56:7 Were you guys high when you went over to that lady's house? \\ 56:8 LM: I didn't go to no lady's house bro. \\ 56:9 MV: What do you mean by we were $h-$ \\ 56:11 high on marijuana then, what does that mean? \\ 56:12 Lorenzo? \\ 56:13 LM: Me, my cousin, my brother, Nick, when we \\ 56:14 were in the car, we were high.}

For MV, the presupposition is such a given that it is not even mentioned. However, he then explicitly and unambiguously links being high on marijuana with going 'over to that lady's house' (56:7), ostensibly seeking information as to whether LM and the others were high when they went, thus presupposing the fact of their having gone there. The explicit nature of this presupposition finally elicits a denial (56:8) from LM in the form of a refusal to cooperate in answering the yes/no question and an overt challenge to the presupposition. MV attempts to salvage his presupposition with a challenge to LM at 56:9-11, in which he appeals to the earlier discourse in which LM appeared to have admitted that he was high at the time of the 'mistake' of going to the crime scene with the others, but is thwarted by LM's explanation at 56:13-14.

When LM makes it clear what the context for being high was and thus disconfirms MV's presupposition, his earlier 'admission' ends up effectively vacated. This apparently does not satisfy MV, however, since he proceeds to resurrect the original presupposition by repeating the question (56:23-24 and 64:2-3) originally posed at 56:7, receiving another emphatic denial from LM:

\section{6:23 MV: You made a mistake. Were you guys high the night you went over to 56:24 her house? \\ 56:26 Lorenzo? \\ 56:27 LM: I didn't go to nobody's house. \\ 64:2 MV: Were you guys high that night when you went up 64:3 there?}

to the murder:

At one point in the interview, MV had suggested a chain of events leading up

$\begin{array}{lll}62: 2 & \text { MV: } & \ldots \text { I } \\ 62: 3 & & \text { think you went to jack the car and it went bad, didn't it? } \\ 62: 5 & & \text { Didn't it? } \\ 62: 6 & \text { LM: } & \varnothing\end{array}$

MV proposes at 62:3 that LM, Nick, and JR went to the house merely to steal the victim's car but that it 'went bad' and resulted in the killing of the victim. Confirmation for this proposal is then sought through the appending of a tag question - notably, however, only seeking 
confirmation to the second part of the proposal, resulting in the transformation of the first part of the proposal into a presupposition that the three had gone to steal the car. Note that an answer of 'no' would have implied that the plan had always been to kill the victim and that one of 'yes' would have constituted an admission that they did kill the victim.

LM was at the victim's house. Having posited with earlier PBQs that LM went to the scene of the crime and having suggested a reason, MM proceeds to ask LM precisely why he was there. MM does this with no less than 11 uses of exactly the same question: 'Why were you there?'

\begin{tabular}{|c|c|c|}
\hline $\begin{array}{l}51: 21 \\
51: 22\end{array}$ & LM: & $\begin{array}{l}\text { Hey, I know I'm goin' for somethin' I didn't do, } \\
\text { though, bro. Sh-- }\end{array}$ \\
\hline $51: 23$ & MM: & Well, why were you there? \\
\hline $51: 25$ & MM: & Why were you there? \\
\hline $51: 27$ & MM: & Lorenzo, why were you there? \\
\hline $52: 1$ & LM: & Stupid, but sh- ... \\
\hline $52: 2$ & MM: & Why were you there? \\
\hline $52: 4$ & MM: & Lorenzo, why were you there? \\
\hline $52: 5$ & LM: & Where? \\
\hline $52: 6$ & MM: & Why were you there at this lady's house? \\
\hline $52: 7$ & LM: & I was not at that lady's house, bro. \\
\hline $52: 8$ & MM: & Lorenzo, your footprint's in the blood. Why were \\
\hline $52: 9$ & & you there? \\
\hline $52: 10$ & & Why were you there, Lorenzo? \\
\hline $52: 11$ & LM: & I wasn't there, bro. Sh- \\
\hline $\begin{array}{l}52: 12 \\
52: 13\end{array}$ & MM: & $\begin{array}{l}\text { Lorenzo, you saw the footprint. We're not - we're } \\
\text { not bullshittin' ya. Why were you there? }\end{array}$ \\
\hline $52: 19$ & MM: & Lorenzo, why were you there? \\
\hline $52: 21$ & & Now you just told me that you'd talk with us with \\
\hline $52: 22$ & & your mom outside of the room. Why were you there? \\
\hline $52: 23$ & LM: & I have nothin' to say 'cause I wasn't there, bro. \\
\hline
\end{tabular}

At no point in this barrage of questions does LM give an answer that confirms the presupposition that he was at the victim's house - with one (likely) exception. After the third utterance of 'Why were you there?' (51:27), LM replies 'Stupid ...'. Unless LM is reflecting on what he perceived to be his stupidity in regard to some other situation or offering an assessment of interview proceedings that he thought were stupid, it seems most likely that he is responding directly to the question as he understood it. Inasmuch as the questioning had just been focusing on the time and place where LM and Nick had allegedly 'hooked up', LM's response is arguably an expression of frustration and regret for having joined Nick for a joyride in the stolen car - that is, his 'there' - during which Nick had divulged details of the crime, a 'stupid' decision that was going to land him in prison (see 51:21). (This interpretation is strengthened by LM's 'Where?' at 52:5, clearly being offered after realizing that he needed to identify what location MM was referring to.) For MM, however, 'there' was, of course, the house where the crime was committed, making LM's response an inadvertent confirmation of the presupposition 
that he was at the crime scene - even though LM (52:7) corrects the record after realizing that MM was referring to the victim's house as 'there'.

The erroneous assumption by LM about the meaning of 'there' in MM's question brings about yet another inadvertent confirmation by LM of the presupposition that LM was at the victim's house. Here, at 53:1-2, MM asks a PBQ which ostensibly seeks information about the logistics of the parties at the crime scene, but which also places LM there:

\begin{tabular}{|c|c|c|}
\hline $\begin{array}{l}53: 1 \\
53: 2\end{array}$ & MM: & $\begin{array}{l}\text { Well, I'm askin' you. What were } \\
\text { the circumstances that brought you there? }\end{array}$ \\
\hline $53: 3$ & LM: & Jus' high w- high off marijuana. \\
\hline $\begin{array}{l}53: 4 \\
53: 5\end{array}$ & MM: & $\begin{array}{l}\text { M'kay, I can understand that. How did ya get } \\
\text { there? }\end{array}$ \\
\hline 53:6 & LM: & $\varnothing$ \\
\hline
\end{tabular}

At 53:2-5, MM again identifies the scene of the crime as 'there'. LM, however, once more misunderstands MM, assuming that he means in the car with Nick and the others, as shown by his response at 53:3. Thus, LM's response again confirms MM's presupposition that he was 'there' at the scene of the crime. MM repeats the presupposition at 53:4-5 in a question ostensibly seeking information on how LM got to the scene.

LM's footprints were found at the scene. At several points in the interview, both MM and MV confront LM with physical evidence purportedly proving that he was at the house, namely, that his 'shoe print' (also variously called 'footprints', 'footprint', and 'shoes') was discovered in the victim's blood at the crime scene. In the following excerpts, this confrontation continues through the use of PBQs:

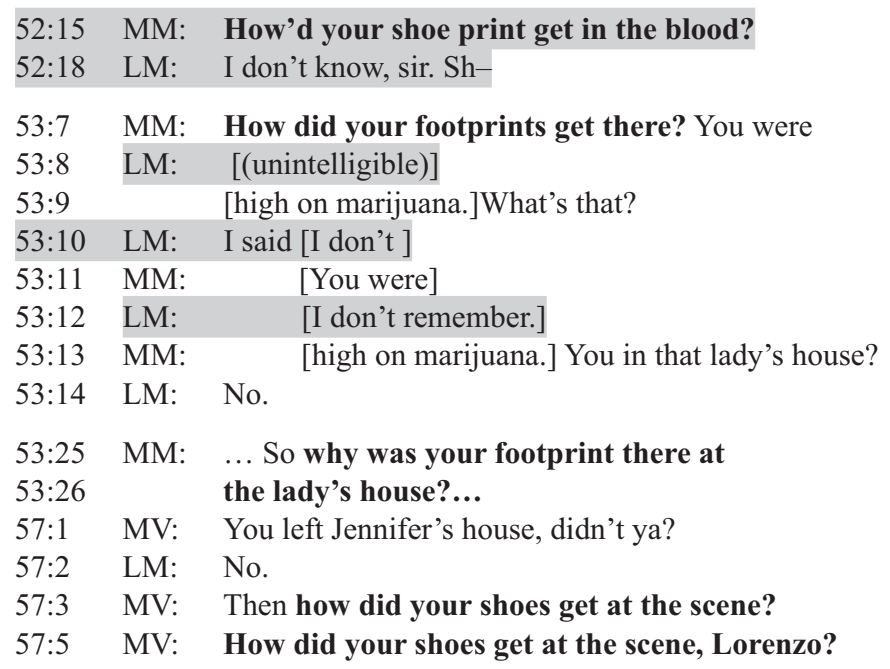

MM's question at 52:15 presupposes that LM's shoe print was in the blood at the crime scene, and LM's response at 52:18 confirms that presupposition. LM's response 
seems to intentionally do so, suggesting that he is willing to admit the possibility that, for example, shoe prints identical to his were at the scene or that the police had wrongly evaluated the prints as identical to his - or perhaps he was simply bewildered. However, at 53:7, MM makes it clear that it was LM's 'footprints' at the scene - in other words, that LM had personally made the prints by stepping in the blood.

Interpreting LM's response at 53:10-12 is problematic. In the first place, it is not clear which question he is responding to - that at $53: 4-5$ or at $53: 7$. He has already admitted to being 'there' with Nick in the stolen car - and note the contextualizing detail by MM at 53:7-9, LM's interpretation of which had involved being with Nick in the stolen car - but it is difficult to imagine how he would claim not to remember how he got 'there' and even more odd how his footprints got 'there'. One possibility is that if LM is certain that MM is asking about being in the car with Nick, he assumes that their questions must be relevant in some way, thus calling for an answer that ends up revealing his confusion. In any case, his reply of 'I don't remember' inadvertently confirms the presupposition that he was 'there' at the house as posited by MM. The next exchange at 53:13-14, however - LM's denial that he was at the house - does confirm his alternative understanding of where 'there' was.

The final PBQ having to do with LM's footprints focuses on how they were cleaned following their alleged encounter with blood:

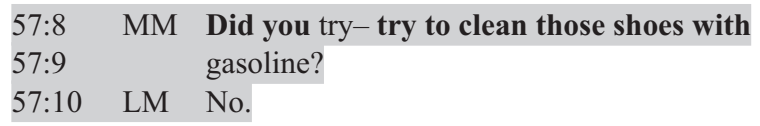

At 57:8-9, the presupposition is contained in the demonstrative 'those', which establishes that the shoes were the ones at the scene of the crime. LM's reply of 'no' to the question of whether he had tried to clean the shoes with gasoline confirms the presupposition that LM's shoes - and thus LM himself - were at the scene. In other words, his shoes were at the scene, but he didn't happen to clean them with gasoline.

\section{LM was directly involved in the murder}

The final global fact asserted by the investigators through the use of PBQs is that LM participated directly and actively in the murder - positing first that he was one of the culpable parties who had an individual part to play in the commission of the crime and then that he had hit the victim, killed (or at least mortally wounded) her, and left her to die.

LM was one of the culpable parties with an individual role in the killing. At 80:1ff, MM ostensibly seeks to establish whether LM was the sole perpetrator on the crime:

$\begin{array}{lll}\text { 80:1 } & \text { MM: } & \text { Lorenzo? Did you do this on your own? } \\ \text { 80:2 } & \text { LM: } & \text { No. } \\ \text { 80:3 } & \text { MM: } & \text { Lorenzo? Did you do this on your own? } \\ \text { 80:4 } & \text { LM: } & \text { No sir. }\end{array}$

The duplicate exchanges at 80:1-2 and 3-4 include both a presupposition that LM did 'this' - that is, participated in the crime, namely murder - and denials that confirm the 
presupposition. Although MM is ostensibly seeking information about whether LM performed the crime 'on [his] own', LM's denial is clearly an attempt to respond to the larger question of whether he did it, which, by so denying, inadvertently confirms the presupposition that he did it - specifically as one of a trio of perpetrators, a group that MV had sought to identify at $65: 1-2$ :

65:1 MV: Okay. Then you guys were all in this together,

65:2 MV: right?

Because MV's second person plural 'you guys' includes Nick and JR and yet only addresses LM, the presupposition here is quite subtle. A 'yes' answer to the question would confirm that LM was 'in this' - that is, the crime - with the others. However, even a 'no' answer would still allow the survival of the presupposition that LM was one of '[the] guys' - the only remaining question being 'Who did what?'.

At 72:14, MV explores what LM's specific role was in the crime:

72:14 MV: What was your part in this whole deal? We know you were there, Lorenzo.

Here, MV's question presupposes that LM indeed had a 'part' in the crime. Note that MV's follow-up statement effectively disallows an answer from LM and leaves the presupposition floating.

Subsequent questions from MV presuppose further that LM had a role in the crime, variously as an 'involvement' ...

84:21 MV: Do you wanna help yourself out and tell us what

84:22 your involvement with this was?

86:10 MV: ... You better tell us what

86:11 your involvement in this murder was,

86:12 so we know who to go after the most.

... what he 'did' ...

84:6 MV: ... You need to get on board and

84:7 tell us what you know and what you did at this murder - ...

$\ldots$ or the extent to which he was a 'player' ...

84:7 MV: ...- -so you can

84:8 help yourself out - to find out if you were the main player here ... Were

84:9 you the main player?

84:10 LM: No.

... or 'man':

84:11 MV: Were you the main man? Did you come up with the

84:12 idea?... 
In response to MV's question at 84:8-9 presupposing LM was a 'player', LM - again in an apparent attempt to deny that he was involved at all - answers 'no', thus confirming the presupposition.

Early in the interview, MM had also sought to identify LM's specific role in the commission of the crime, presupposing that LM helped the others in some way:

44:21 MM: What'd you help 'em with?

44:22 LM: I wasn't there! commission of the crime:

At 71:6-21, MM and MV explore further what role LM played in the

71:6 MM: You helped drag her out.

71:10 MM: Lorenzo, you helped drag her out, didn't you?

71:11 LM: No sir!

71:12 MV: Those shoes are o- are the drag shoes. `Didn't

71:13 ya?

71:15 MV: Lorenzo?

71:16 MM: Was that your input?

71:17 LM: No.

71:18 MM: Your job was just to drag her out?

71:19 LM: No.

71:20 MM: So you had somethin' to do with killin' her?

71:21 LM: No.

The question at 71:16 presupposes that LM had specific 'input' into the crime and seeks only to discover whether dragging the victim out was the only input. LM's answer of 'No' at 71:17 - again, an attempt to address the larger question of whether he was involved at all - confirms the presupposition. The next exchange (71:18-19) realizes the same dynamic: MM presupposes that LM had a 'job' to perform in the commission of the crime, and LM - seeking to deny any involvement at all - confirms the presupposition with his answer of 'No'.

The inclusion of 'just' in MM's question at 71:18 sharpens the presupposition of LM's having had a 'job' - that is, that LM indeed had the job of dragging her out and perhaps had another job as well. This interpretation is supported by MM's next question at 71:20: in light of LM's denial that his job was 'just' to drag the victim out, MM takes the next step of concluding that LM had something to do with the actual killing.

At 60:23 and 25, MV presupposes that Lorenzo participated in dragging the victim out of the house and ostensibly only wants to find out whether he did it alone - again employing 'just':

60:23 MV: How many drug her out? You? Just you alone?

60:25 MV: Did you drag her out alone Lorenzo?

LM participated out of intimidation or to show solidarity. In the following excerpts, MM and MV employ a familiar technique of minimization in which explanations or excuses for committing the crime are suggested to the suspect in an attempt to make it easier to admit guilt. The minimizations here include suggestions that LM was involved because (1) he was afraid 
of the others, (2) they made him do it, (3) he would have been beaten up if he had refused to help, (4) his involvement was a way of showing friendship, and (5) he was trying to prove something to them. All of these suggestions are made through the use of PBQs:

\section{2:7 MM: Are you so afraid of these guys, that these guys \\ 62:8 told you to do it an' you had to do it because you're afraid of 'em? \\ 62:9 MV: You went in, didn't you? You guys were just gonna \\ 62:10 jack the car and it went to shit, huh?}

MM's first question (at 62:7-8) is structurally complicated. First, by asking LM if he is 'so' afraid of Nick and JR, he presupposes that he is afraid and then proceeds to explore the reason. The next clause, beginning with 'that', although appearing in sequence to suggest a result of LM being afraid, instead introduces a new topic - LM having been told to 'do it', that is, participate in the crime. The next clause, beginning with 'you', gives the result of LM being afraid - that is, that he had to do it. This is confirmed by the 'because' clause. The entire question seeks a yes/no answer. Either answer, however, would strictly address only whether or not LM was afraid, leaving as presupposed that he had to do it - and thus did it - as well as that he was afraid.

At 62:9-10, MV essentially repeats MM's question at 62:2-3 (see earlier). The inclusion of 'just', however, creates a presupposition that they had intended only to steal the car. Similar to the effect of the tag question at 62:3, 'Huh?' seeks a yes/no answer, either of which would support the presupposition:

$\begin{array}{lll}\text { 63:23 } & \text { MV: } & \text { Did they make you do it? } \\ \text { 63:24 } & \text { LM: } & \text { No. } \\ \text { 63:25 } & \text { MM: } & \text { I know you're afraid of 'em. Huh? } \\ \text { 63:26 } & \text { MV: } & \text { They didn't make you do it? } \\ \text { 63:27 } & \text { MM: } & \text { You're afraid of 'em. Did they make you do it? }\end{array}$

MV's question at 63:23, using the causative verb 'make', presupposes that LM did it and ostensibly only seeks yes/no information on whether or not they made him do it. In his attempt at 63:24 to deny that he did it, LM instead inadvertently confirms the presupposition that he did. MV repeats the presupposition at 63:26, using a declarative question to confirm LM's 'admission'. MM then asks (63:27) the same question as MV's at 63:23, along with its presupposition. Answers of 'yes' or 'no' to either question would confirm the presupposition.

\begin{tabular}{|c|c|c|}
\hline 64:18 & MM & They were gonna beat ya up if you didn't help 'em. \\
\hline 64:19 & & Isn't that right? \\
\hline $\begin{array}{l}64: 21 \\
64: 22\end{array}$ & MM: & $\begin{array}{l}\text { Isn't that right Lorenzo? They were gonna beat } \\
\text { you up if you didn't help 'em. }\end{array}$ \\
\hline $64: 23$ & LM: & No. \\
\hline $\begin{array}{l}64: 24 \\
64: 25\end{array}$ & MM: & $\begin{array}{l}\text { Lorenzo, you're afraid of Nick; you just got done } \\
\text { tellin' me that. }\end{array}$ \\
\hline
\end{tabular}

MM at 64:18-22 presupposes that LM helped the others in the commission of the crime and suggests another possible explanation: that they were going to beat him up if he didn't help. LM's attempted global denial at 64:23 again confirms the presupposition. 
At 65:18ff, MM explores a new reason for LM doing what he did, that is, to prove something,

\begin{tabular}{|c|c|c|}
\hline $65: 18$ & MM: & Were you supposed to prove somethin' to them to \\
\hline $65: 19$ & & do it that night? \\
\hline $65: 21$ & & What did they want you to prove? \\
\hline $65: 23$ & & Were you tryin' to prove somethin' that night? \\
\hline 65:25 & & What were you tryin' to prove? \\
\hline $65: 26$ & LM: & Tryin' to prove nothin'. \\
\hline $65: 27$ & MV: & Then why did you guys go over there? \\
\hline $66: 1$ & LM: & I didn't go nowhere. \\
\hline
\end{tabular}

in the process presupposing through yes/no PBQs at 65:18-19 and 23 that LM did it. LM's presupposed actions are referenced in 'that night' and 'what'. Note that at 65:21 and 25, wh-questions are employed which contain the presupposition that LM was trying to prove something - the only question being what. This combination of yes/no questions and wh-questions allows the investigators to posit both that LM did it and that he did it to prove something.

At 65:26, LM's answer, 'Tryin' to prove nothin" (which again is intended to indicate that he didn't $d o$ anything), while disconfirming the presupposition that he did it to prove something, ends up inadvertently confirming the presupposition that he was in fact involved in the activities of 'that night'. This is made clear by MV's follow-up question at 65:27, which ostensibly seeks information on the real reason for them having gone 'over there' - again, a fact presupposed. LM's denial at 66:1 shows another of his infrequent refusals to accept the presupposition.

At 62:13, MM presupposes, by means of ostensibly trying to find out 'how', that the three became friends:

\section{2:13 MM: Is that how you became friends? I mean they \\ 62:14 wanted you to do this ... so that you'd be friends with them? \\ 62:15 LM: No.}

'[T]hat' refers to what LM 'did', thus repeating the presupposition. In the next question (62:13-14), MM presupposes that Nick and JR wanted LM to 'do this' - again referring to what LM 'did'. LM's answer of 'No' at 62:15 appears to serve as a global denial of having been involved at all, but it only functions to deny that the reason for him doing what he did was so that he would be friends with the others, thus confirming the presupposition.

LM was actively involved in the killing. In an attempt to find out whether LM was the first to hit the victim, MV's questions (at 66:17, 19-21, 21-23, and 25) and MM's (at 84:12) thus presuppose that LM did indeed hit her:

66:15 MV: Huh? Who hit her first?

66:17 You? Did you hit her first?

66:18 LM: I didn't hit nobody man. I wasn't even ... 


$\begin{array}{lll}66: 19 & \text { MV: } & \text { Didja hit her ... } \\ 66: 20 & \text { LM: } & \ldots \text { there. } \\ 66: 21 & \text { MV: } & \text {.. first? Didja ... } \\ 66: 22 & \text { LM: } & \text { I wasn't even there ... } \\ 66: 23 & \text { MV: } & \text {... hit her first? } \\ 66: 24 & \text { LM: } & \text {.. I wasn't there. } \\ 66: 25 & \text { MV: } & \text { You were there. Did you hit her first? } \\ 66: 26 & \text { LM: } & \text { I wasn't there. } \\ 84: 12 & \text { MV: } & \text {... Did you give the first hit? }\end{array}$

At 71:22 and 24, MM presupposes again that LM hit the victim and ostensibly only seeks to find out whether he did it with a shoe or a rock:

$\begin{array}{lll}\text { 71:22 } & \text { MM: } & \text { You hit her over the head with a shoe? } \\ \text { 71:23 } & \text { LM: } & \text { No sir. } \\ \text { 71:24 } & \text { MM: } & \text { You hit her with a rock? } \\ \text { 71:25 } & \text { LM: } & \text { No sir. }\end{array}$

Yet again, LM's attempts (at 71:23 and 25) to deny any involvement at all end up confirming the presupposition that he was involved, that is, that he had hit the victim with something.

In the following excerpts, LM is asked 15 questions which presuppose that he killed the victim. The first three (at 58:2, 5, and 18) seek confirmation - through the use of the tag 'didja' - that LM didn't 'want' to kill the victim:

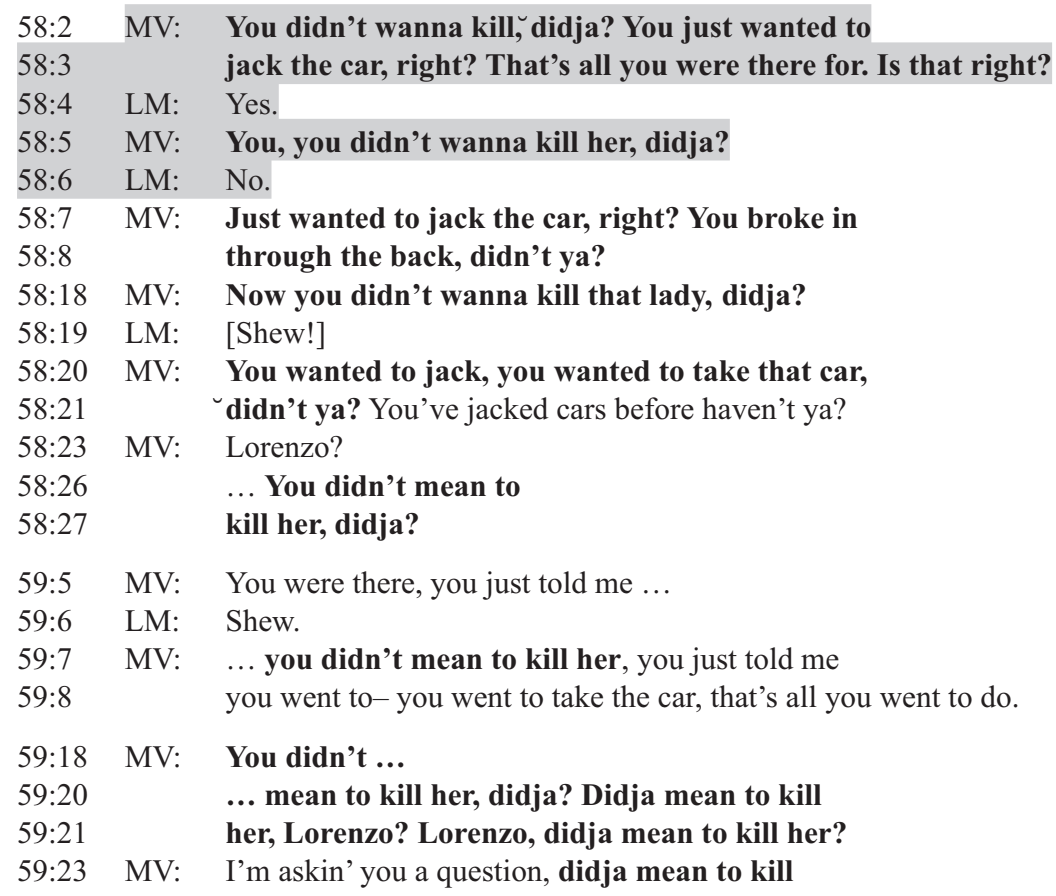




\begin{tabular}{|c|c|c|}
\hline 59:24 & & her? \\
\hline $59: 25$ & LM: & I didn't kill nobody man! Sh- ... \\
\hline 60:7 & MV: & ... Did you mean \\
\hline $60: 8$ & & to kill her when you went to jack the car? \\
\hline 60:10 & MV: & Lorenzo, didja mean to kill her? \\
\hline 60:11 & LM: & I wasn't even there, so why do I \\
\hline 60:12 & & have to say that? \\
\hline $\begin{array}{l}60: 15 \\
60: 16\end{array}$ & MV: & $\begin{array}{l}\text { Lorenzo? You've already answered me once, you } \\
\text { didn't mean to kill her, did you? }\end{array}$ \\
\hline $\begin{array}{l}62: 26 \\
62: 27\end{array}$ & MV: & $\begin{array}{l}\text { You better cop out dude, who did that. 'Cause } \\
\text { you didn't mean to do it, didja? Didja, Lorenzo? }\end{array}$ \\
\hline $63: 2$ & MV: & Did you mean to kill her? \\
\hline $\begin{array}{l}63: 4 \\
63: 5\end{array}$ & MV: & $\begin{array}{l}\text { Is that what you guys were after in the first } \\
\text { place, was to kill her? Huh? }\end{array}$ \\
\hline 63:6 & LM: & I didn't kill nobody man, sh- ... \\
\hline $66 \cdot 4$ & MV: & I wanna know if you meant to kill this lady. \\
\hline & LM: & I didn’t kill no lady. \\
\hline $66: 6$ & MV: & Did you mean to kill her? \\
\hline
\end{tabular}

LM's answer of 'yes' at 58:4 confirms the presupposition in 58:2-3 that LM was 'there' at the house for the original purpose of jacking the car. However, as we have seen, LM's understanding of 'there' is being with Nick in the car; thus, it is somewhat unexpected that LM would admit to wanting to jack the car. A possible explanation may be found in 58:2 with the first instance of LM being asked whether he wanted to kill the victim. In this instance, the question does not include 'her' which the many following questions do include. Perhaps LM understood the question as MV's assumption that he did not join Nick in the car with the intention of killing anyone.

However, when MV includes 'her' in his next question (58:5), LM's answer of 'No' appears to confirm the presupposition that he did kill the victim even though he didn't want to - thus producing the most damaging (apparent) admission of the entire interrogation. Since this fatal exchange occurs in the midst of a continuous stream of denials by LM that he was involved in the crime, it seems again quite unexpected that LM would appear to make such an admission. In fact, it is clear that he did not. Support for this interpretation is found at 59:25, where LM emphatically denies that he killed the victim. The apparent contradiction is explained again by a misinterpretation of the question on LM's part. His response of 'No' at 58:6 does not mean that he killed her even though he didn't want to, but rather that he was not interested at all in being involved in the murder ... because he wasn't involved.

MV, however, takes LM's reply at 58:6 as a confirmation that he killed the victim. At 58:18, MV again seeks confirmation from LM but does not get it, instead eliciting a response of apparent frustration or distress. This is explained by that fact that when MV inserts at 58:7-8 the claim that LM broke into the house, LM apparently becomes aware that MV's question indeed assumes that he did kill the victim.

A critical reformulation occurs at 58:26-27: rather than seeking confirmation from LM that he killed the victim even though he didn't 'want' to, MV changes his wording to 
seek confirmation that LM killed the victim even though he didn't 'mean' to. This change from the somewhat less factive verb 'want' to the clearly factive verb 'mean' allows MV, at 59:5-7, to argue for LM having admitted to murder.

Finally, the following three questions from MM presuppose that LM left the victim and ostensibly only seeks to discover whether she was dead when he did so:

\section{5:4 MM: Lorenzo? Was she dead when you left her? \\ 75:6 Lorenzo? Was she dead when you left her? \\ 75:9 ... Was she dead \\ 75:10 when you left her?}

\section{Discussion and conclusion}

Social scientific studies of police interrogation in the United States (see e.g. Davis, 2010; Gudjonsson, 2006; Kassin and McNall, 1991; Leo, 2008; Leo and Drizin, 2010; Meissner and Russano, 2003, among many others) have shown that police investigators employ a wide range of interrogation techniques in their efforts to extract a confession from a suspect. Such techniques can be grouped broadly under the dual categories of maximization - in which interrogators seek to maximize the seriousness of consequences associated with continued denial of guilt and use intimidation tactics such as presenting false evidence, accusing the suspect of being guilty, and refusing to tolerate denials - and minimization - in which interrogators seek to minimize the degree of responsibility of the suspect for the crime and/or the level of consequence if the suspect confesses.

Among the many maximization techniques used by police interrogators is that of communicating certainty of the suspect's guilt. In outlining the steps of the guiltpresumptive phase of interrogation, Meissner et al. (2009) note that it generally includes 'confronting the suspect with a firm belief in their culpability for the crime' (p. 5). The investigator 'accuses the suspect of the crime' and 'expresses certainty in that opinion' (Kassin, 2006: 216). Such certainty is typically expressed by investigators saying that they 'know' that the suspect did it - that is, either committed the crime or performed some action associated with the crime. However, in the LM interrogation, such overt assertion of certainty is rare: in an interview transcript of 141 pages, investigators (specifically MV and an occasional participant named Priest) said only six times that they 'knew' of Lorenzo's involvement, and their apparent knowing was limited to Lorenzo being at the victim's house. At no time do the investigators directly express certainty of Lorenzo's guilt for committing the crime or of any other matter besides him being at the victim's house.

This analysis has shown, however, that despite the virtual absence of direct expressions of certainty of the suspect's guilt, investigators do express indirectly their certainty about a great number of things through the use of the many PBQs used in the interrogation. On the surface, of course, interrogative sentences generate speech act questions which function to seek information, and in the LM interrogation, the vast majority of the questions asked by MM and MV do exactly that. However, in addition, 117 of their questions also include presuppositions, which, as Stalnaker (1978) has pointed out, 'are taken by the speaker to be the common ground of the participants in the conversation' (p. 321). Thus, even in an information-seeking question, there is no question about the truth of a 
presupposition that may be embedded in it - at least from the standpoint of the speaker; what is presupposed is assumed to be certain. This makes a presupposition 'a powerful instrument in the implicit assertion of debatable propositions' (Ehrlich and Sidnell, 2006: 659, citing Van Dijk, 1991).

This power of implicit assertion in the LM interrogation functions in two ways. First, it enacts the common maximization technique of expressing certainty of the suspect's culpability for various aspects of the crime. For example, in the question 'Did you drag her out alone, Lorenzo?', the investigator presupposes and thus expresses certainty that Lorenzo at least helped to drag the victim out of the house. This constitutes a serious accusation of wrongdoing - a classic maximization technique. In addition, however, even more pressure is applied to the suspect when such an accusation is embedded in a question, any direct answer to which confirms the presupposition, forcing the suspect to either refuse to answer a direct, 'highly controlling' (Ehrlich and Sidnell, 2006: 658) question (an act interpretable as evasion or insolence) or answer it to his or her peril, that is, by effectively giving an admission to the accused action. Moreover, as we have seen again and again in the LM interrogation, the use of PBQs - some of which are structurally complicated - puts the suspect at risk of becoming confused by the question, often resulting in the production of an answer which seeks to respond to the information the suspect thinks the interrogator is seeking, but instead inadvertently confirms a damaging presupposition.

A second function of PBQs is to assert propositions that - whether the suspect answers the question or not - constitute key components of the interrogation record. In cases where the suspect is innocent of the charge being levied in the presupposition, too often 'hearers [e.g., possibly potential prosecutors, judges, and jurors] behave as if speakers' presuppositions are to be accepted' (Brown and Yule, 1983: 30); on this point, Ehrlich and Sidnell (2006: 659) cite Chilton's (2004) argument that 'presuppositions contribute "to the building of a consensual reality"' (p. 64). Such an inclination toward consensus on the content of presuppositions is strengthened greatly, of course, when a significant number of PBQs receive answers that - even inadvertently and thus unintentionally - confirm their presuppositions, as is the case in the LM interview. The question of the strength of such a psychological effect in this case is moot, however, since at a point about two-thirds of the way through the interrogation, Lorenzo gave up his resistance, ceased his denials, and gave the investigators the answers they were looking for, fully implicating himself in the murder as far as the official record was concerned. As was mentioned, overwhelming evidence to the contrary later exonerated Lorenzo; however, as has too often been the case, a youth - a member of a population known to be especially vulnerable to the effects of coercive interrogation - had been psychologically manipulated, primarily through the use of a specific maximization technique which exploited the use of presupposition-bearing questions, to confess to a crime he didn't commit.

\section{Declaration of conflicting interests}

The author(s) declared no potential conflicts of interest with respect to the research, authorship, and/or publication of this article.

\section{Funding}

The author(s) received no financial support for the research, authorship, and/or publication of this article. 


\section{Notes}

1. This summary is adapted from the Lorenzo Montoya case report prepared by Maurice Possley of the National Registry of Exonerations, originally posted to the NRE website on 19 June 2014 and updated on 17 June 2016.

2. The copy of the police transcript used for this analysis was obtained from attorney Lisa Polansky, as were copies of the videotape.

\section{References}

Belnap N (1966) Questions, Answers, and Presuppositions. Journal of Philosophy 63(20): 609-611. Brown G and Yule G (1983) Discourse Analysis. Cambridge: Cambridge University Press.

Chilton P (2004) Analysing Political Discourse. Abingdon: Psychology Press.

Davis D (2010) Lies, Damned Lies, and the Path from Police Interrogation to Wrongful Conviction. In: Gonzales M, Tavris C and Aronson J (eds) The Scientist and the Humanist: A Festschrift in Honor of Elliot Aronson. Abingdon: Psychology Press, pp. 211-247.

Presupposition and Interrogation: The Formation of Yes/No Questions: Some Unexpected Restrictions and What They Can Teach Us', Working Papers in Linguistics, University of Trondheim.

Ehrlich S and Sidnell J (2006) 'I think that's not an assumption you ought to make': Challenging Presuppositions in Inquiry Testimony. Language in Society 35(5): 655-676.

Gudjonsson GH (2006) The Psychology of Interrogations and Confessions. In: Williamson T (ed.) Investigative Interviewing: Rights, Research and Regulation. London: Willan Publishing, pp. 123-146.

Kassin SM (2006) A Critical Appraisal of Modern Police Interrogations. In: Williamson T (ed.) Investigative Interviewing: Rights, Research and Regulation. London: Willan Publishing, pp. 207-228.

Kassin SM and McNall K (1991) Police Interrogations and Confessions: Communicating Promises and Threats by Pragmatic Implication. Law and Human Behavior 15(3): 233-251.

Leo RA (2008) Police Interrogation and American Justice. Cambridge, MA: Harvard University Press.

Leo RA and Drizin SA (2010) The Three Errors: Pathways to False Confession and Wrongful Conviction. in: Lassiter D and Meissner CA (eds) Police Interrogations and False Confessions: Current Research, Practice, and Policy Recommendations. Washington, DC: American Psychological Association, pp. 9-30.

Levinson S (1983) Pragmatics. Cambridge: Cambridge University Press.

Meissner CA and Russano MB (2003) The Psychology of Interrogations and False Confessions: Research and Recommendations. Canadian Journal of Police and Security Services 1(1): 53-63.

Meissner CA, Horgan AJ and Albrechtsen JS (2009) False Confessions. In: Kocsis RN (ed.) Applied Criminal Psychology: A Guide to Forensic Behavioral Sciences. Springfield, IL: Charles C. Thomas, pp. 199-210.

Stalnaker R (1978) Assertion. In: Cole P (ed.) Linguistics: Syntax and Semantics, Vol. 9: Pragmatics. Cambridge, MA: Academic Press, pp. 315-332.

Van Dijk T (1991) Racism and the Press. London: Routledge.

\section{Author biography}

Philip Gaines is Professor of English at Montana State University. His research and scholarship focuses on the discursive structures and processes of trial attorneys and police investigators. Among his most recent work is a monograph with Oxford University Press, From Truth to Technique at Trial: A Discursive History of Advocacy Advice Texts (2016). He is currently at work on a book, on the discourse of police interrogations that lead to false confessions. 